\title{
Intertidal surfgrass as an allochthonous resource trap from the subtidal habitat
}

\author{
Masakazu Hori* \\ Laboratory of Biodiversity Science, School of Agriculture and Life Science, The University of Tokyo, Bunkyo-ku, \\ Tokyo, 113-8657, Japan
}

\begin{abstract}
Seagrasses have many important ecological functions in regulating community structure and production in nearshore systems, but little is known about their architectural role as allochthonous resource traps. I experimentally manipulated stands of surfgrass shoots in tide pools of the intertidal rocky bench to determine whether surfgrass trapped 2 types of allochthonous resources (subtidal sea urchins and algal drifts) and thus facilitated 2 recipient consumers (carrion crows and herbivorous gastropods). One experiment revealed that the quantity of sea urchins was significantly higher in tide pools with surfgrass shoots than in those without and was positively correlated with shoot density. In addition, the foraging frequency of crows on sea urchins was significantly higher in tide pools with surfgrass than in those without. Another experiment revealed that the quantity of algal drift was significantly higher in tide pools with surfgrass shoots than in those without, and was positively correlated with mean shoot length. Moreover, the number of gastropods in tide pools with surfgrass was significantly higher than in those without surfgrass, even over the short term. Furthermore, gastropod numbers in tide pools with surfgrass were higher $1 \mathrm{yr}$ after the experiment had ended. Therefore, I conclude that surfgrass plays an important architectural role in regulating allochthonous resource input and may influence the behavior and growth of recipient consumers by modifying allochthonous resource subsidies.
\end{abstract}

KEY WORDS: Allochthonous input - Seagrass $\cdot$ Ecosystem function $\cdot$ Surfgrass $\cdot$ Sea urchin $\cdot$ Algal drift $\cdot$ Carrion crow $\cdot$ Gastropod

\section{INTRODUCTION}

Almost all natural ecosystems are open and frequently interact with other ecosystems in various ways, for example, through the flow of nutrients and organic materials across ecosystem boundaries (Polis \& Hurd 1996, Polis \& Strong 1996). These allochthonous resources often facilitate recipient (in situ) organisms and indirectly influence other organisms that interact with the recipient organisms (Polis \& Hurd 1995, Polis et al. 1997), indicating that allochthonous input may have important effects on community structure, dynamics, and ecosystem functioning. Rocky intertidal habitats receive various allochthonous resources (Menge \& Branch 2001). For example, upwelling nutrients from deep-sea systems sometimes regulate the spring blooms of algal produc- tion (Menge et al. 1997a). Phytoplankton from pelagic systems and detritus derived from subtidal kelp beds are major food resources for filter-feeding species (Duggins et al. 1989, Bustamante \& Branch 1996, Menge et al. 1997b). In addition, kelp drifts from subtidal systems occasionally facilitate grazer abundance at a higher level than that which can be maintained by in situ algal production alone (Bustamante et al. 1995, Bustamante \& Branch 1996). These facts indicate that allochthonous subsidization may be an important factor in regulating the structure and dynamics of rocky intertidal communities (Menge \& Branch 2001). However, little is known about the processes of allochthonous resource supply, for example, how allochthonous inputs are captured in intertidal habitats, and what factors regulate the amount of allochthonous input into intertidal habitats. 
Seagrasses are important aquatic phanerograms that have various ecological functions in nearshore ecosystems, enabling them to sustain high secondary production and diversity (Fredette et al. 1990, Heck et al. 1995). In particular, much attention has focused on their architectural roles, such as habitat provision for both auto- and heterotrophic organisms (Williams \& Heck 2001). The surfgrass Phyllospadix iwatensis typically occurs in the intertidal and upper-subtidal zone of rocky shores (Turner 1985, Hasegawa et al. 2005). The morphological characteristics of this surfgrass differ from those of other seagrass species in that it inhabits muddy/sandy habitats, e.g. its shoots are relatively tough, enabling this plant to sway under strong wave action during high tide and to withstand severe heat and drought during low tide (Yabe et al. 1995). These characteristics make it possible for this species to provide a 3D structure during high tide even on waveexposed shores, along with other seagrass species that occur in wave-protected areas. Therefore, surfgrass seems to have architectural functions similar to those of other seagrass species, but little is known about its ecological functions.

In this study, I determined whether surfgrass has important architectural functions by trapping allochthonous resources moving from subtidal to intertidal habitats, and facilitating the recipient intertidal consumers. By manipulating stands of surfgrass shoots, I experimentally tested whether they affected allochthonous resource input and foraging behavior (functional aspects) and/or the density and growth (numerical aspects) of recipient consumers by modifying the amount of allochthonous resources; it has been shown that recipient consumers may show functional and/or numerical responses to allochthonous input (Sabo \& Power 2002a, 2002b)

\section{MATERIALS AND METHODS}

The study was conducted on the flat tuffaceous benches (4.8 ha) of the Hiura rocky shore in southern Hokkaido, Japan $\left(41^{\circ} 44^{\prime} \mathrm{N}, 141^{\circ} 04^{\prime} \mathrm{E}\right)$, which contain many tide pools with the surfgrass, Phyllospadix iwatensis, in the mid- and lower intertidal zone. This surfgrass species is the most dominant perennial plant distributed in the intertidal zone and is not grazed by any herbivores in this region (Hori 2003). The intertidal habitat of this shore has 2 major abundant allochthonous resources: sea urchins and shore algal drift from subtidal habitat. The sea urchins Strongylocentrotus intermedius and $S$. nudus passively migrate from subtidal systems, fall into these tide pools at high tide, mainly during the spring and summer, and are eaten by carrion crows Corvus corone during low tide (Hori
2003). Sea urchins that are not eaten by birds die because of the heat and drought in the intertidal habitat from spring to autumn. This suggests that sea urchins cannot inhabit the intertidal zone and are thus an allochthonous resource from adjacent habitats in this region (Hori \& Noda 2001, Hori 2003). Two pairs of carrion crows established their breeding territories in the area, preventing any other crows from foraging there, so that only the functional aspects of their foraging on the sea urchins could be observed during this study. However, shore algal drift, primarily subtidal brown kelp (Laminaria spp. and Alaria spp.), is often transported from the subtidal to the intertidal system by wave action and is also found in the pools, mainly between summer and autumn (Hori 2003). The algae are consumed by herbivorous gastropods Chlorostoma spp., which are the dominant herbivores in these crevices.

Field experiments. The 2 field experiments were performed from April 2001 to August 2002. One experiment was designed to investigate the effects of surfgrass on sea urchin and crow foraging, and the other investigated the effects of surfgrass on algal drift and gastropods. Before starting the experiments, 24 randomly located tide pools containing surfgrass on the intertidal rocky benches were chosen. Half of these pools were $<30 \mathrm{~cm}$ in depth (shallow tide pools), which allowed carrion crows to feed on sea urchins, while the other half were $>30 \mathrm{~cm}$ in depth (deep tide pools), which were too deep for the crows to forage on sea urchins. The surface areas of these tide pools were similar, between 1.18 and $1.4 \mathrm{~m}^{2}$, and thus most results are presented as number per tide pool. Surfgrass shoots were continuously cut down in 6 pools of both depths (without shoot tide pools), and shoots were retained in another 6 pools of both depths (with shoot tide pools). In the pools in which the shoots were not cropped, the length of the shoot stand protruding from the tide pool surface during high tide and the shoot density were measured at the end of the experiments.

The first experiment investigated the relationships among surfgrass, sea urchin input, and crows foraging on sea urchins. All sea urchins were removed completely from all experimental tide pools, and after 2 weeks the number of sea urchins in each pool was recorded. Because sea urchins $<30 \mathrm{~mm}$ diameter are not eaten by crows (Hori \& Noda 2001), sea urchins were classified into 2 size classes: $>30 \mathrm{~mm}$ and $<30 \mathrm{~mm}$ in diameter. At the same time, crows foraging on sea urchins were observed in the shallow tide pools. Using a 20 to $60 \times$ spotting scope, observations were conducted 3 times after sea urchin removal: at 7, 10, and $14 \mathrm{~d}$. At each observation (during daylight ebb tide), the number of sea urchins consumed by the crows were counted for all experimental tide pools. 
These manipulations and observations were repeated 4 times in 2001: 19 April to 2 May, 4 to 17 May, 19 May to 1 June, and 3 to 16 June.

To investigate the relationships among surfgrass, algal drift input, and gastropod density, 2 sequential experiments (1 short and 1 long period) were performed in the same tide pools that had been used for the sea urchin experiment. Since herbivorous gastropods normally live in tide pools, the shoot-cutting manipulation alone may have had some effects on their survival (e.g. by increasing heat stress). In addition, environmental stress is likely to be more extreme in shallow tide pools than in deep ones, because of the reduced volume of water. Therefore, the experimental manipulations of algal drifts and gastropods were conducted over 2 periods, one short and one long, as described below.

At the beginning of the short-term experiment, all algal drifts and herbivorous gastropods were removed from all experimental tide pools. The experimental manipulation was performed as a full factorial design (with and without algae, surfgrass, or gastropods), with 2 shallow and 2 deep tide pools with and without surfgrass for each treatment. Algae and gastropods were removed every $2 \mathrm{~d}$ for $14 \mathrm{~d}$ as follows: Treatment 1 (gastropods and algae removed), Treatment 2 (algae only removed), and Treatment 3 (algae and gastropod not removed: control). Each treatment therefore included 8 tidal pools. Treatment 1 was designed to allow evaluation of the effects of shoot cutting on the algal drift input. The number of gastropods was counted after $14 \mathrm{~d}$ in each tide pool in Treatments 2 and 3 .

All algal drifts removed from tide pools in Treatments 1 and 2 were collected and oven-dried at $60^{\circ} \mathrm{C}$ for $48 \mathrm{~h}$ and then weighed. This manipulation experiment was conducted once from 18 June to 1 July, once from 17 to 30 July, and once from 17 to 30 August 2001. These 3 sets of data were regarded here as temporal replications of the experiment to compensate for the lack of spatial replications.

In addition to the above short-term experiment, an experiment was conducted evaluating the long-term effects of surfgrass shoots and algal drifts on gastropod growth and density with the shoot-cutting and algaldrift manipulations over a 1 yr period. In late August 2001, all algal drifts and gastropods were again removed from all tide pools. Then the algal drifts were continuously removed as frequently as possible, at approx. 4 d intervals, from 3 with-shoot and 3 withoutshoot tide pools of both depths; they were retained in the other with-shoot (3) and without-shoot (3) tide pools of each depth. In August 2002, numbers and shell widths of the gastropods in all tide pools were measured.
Data analysis. Three analyses were performed to clarify the relationships among shoot-cutting, sea urchin input, and crow foraging. First, the linear relationship between the number of sea urchins and the characteristics of surfgrass shoots (shoot density and mean shoot length) was analyzed. Second, the difference in the number of sea urchins between the withand without-shoot tide pools was analyzed by a nested ANOVA. This analysis was performed with the depth and the shoot-cutting manipulation as fixed factors, each experimental period as nested-block factors, and the number of sea urchins as the dependent variable. In this analysis, the data for the number of sea urchins with diameters $<30 \mathrm{~mm}$ and those with diameters $>30 \mathrm{~mm}$ were $\log (\mathrm{N}+1)$-transformed to meet the assumption of homogeneity of variance. Third, the difference in the number of sea urchins consumed by crows between the with- and without-shoot shallow tide pools was analyzed by nested ANOVA. In this analysis, the shoot-cutting manipulation was adopted as the fixed factor, the experimental periods were the nested-block factors, and the number of sea urchins consumed by crows was the dependent variable. Assumption of homogeneity of variance in these analyses was assessed using Cochran's $C$-test.

In the investigation of relationships among shootcutting, algal drift, and herbivorous gastropods, the following 4 analyses were performed. First, the linear relationship between the amount of algal drift and the characteristics of surfgrass shoots was analyzed. Second, the difference in the amount of algal drift between the with- and without-shoot tide pools was analyzed by a 3-way ANOVA using data from Treatments 1 and 2. This analysis was performed with depth, the shoot-cutting manipulation, and the absence/presence of the gastropods adopted as fixed factors and the amount of algal drift occurring during each experimental period as the dependent variable. In this analysis, the amount of algal drift was $\log (\mathrm{N}+1)$ transformed to meet the assumption of homogeneity of variance. Third, 2-way ANOVAs were performed to estimate the effects of surfgrass shoots on the gastropods: one analysis used data from Treatment 2 and the other used data from the control treatment. In these analyses, the shoot-cutting manipulation and depth were adopted as fixed factors, and the number of gastropods was the dependent variable. Fourth, the longterm effects of the shoot-cutting and algal-drift manipulations on the abundance and shell size of gastropods were analyzed by MANOVA, with the shoot-cutting manipulation, presence/absence of algal drift, and depth adopted as fixed factors, and both the abundance and shell width of gastropods as the dependent variables. In these analyses, the assumption of homogeneity of variance was assessed using Cochran's $C$ - 
test. In addition, the assumption of equal variancecovariance matrices for MANOVA was analyzed using Box's $M$-test.

\section{RESULTS}

Sea urchin input into tide pools was positively related to surfgrass shoot density (Fig. 1a), but showed no clear relationship to mean shoot length (Fig. 1b). The number of sea urchins $>30 \mathrm{~mm}$ in diameter was significantly higher when shoots were present than when they were absent, and was significantly higher in deep tide pools (Fig. 2a, Table 1), but there was neither an interactive effect between the shoot-cutting treatment and depth nor a difference between experimental periods. The number of sea urchins $<30 \mathrm{~mm}$ in diameter was significantly higher in tide pools where shoots were present, but did not differ with depth or experimental period (Fig. 2b, Table 1). In addition, the carrion crows Corvus corone foraged significantly more and consumed many more sea urchins in shallow tide pools with surfgrass shoots than in those without (nested ANOVA; $F=118.163, \mathrm{p}<0.0001$, Fig. 3), and this difference did not change between experimental periods $(F=0.354, \mathrm{p}=0.9031)$.

The amounts of algal drift entering the tide pools over the 2 wk periods were significant and positively related to the mean shoot length of surfgrass (Fig. 1d),
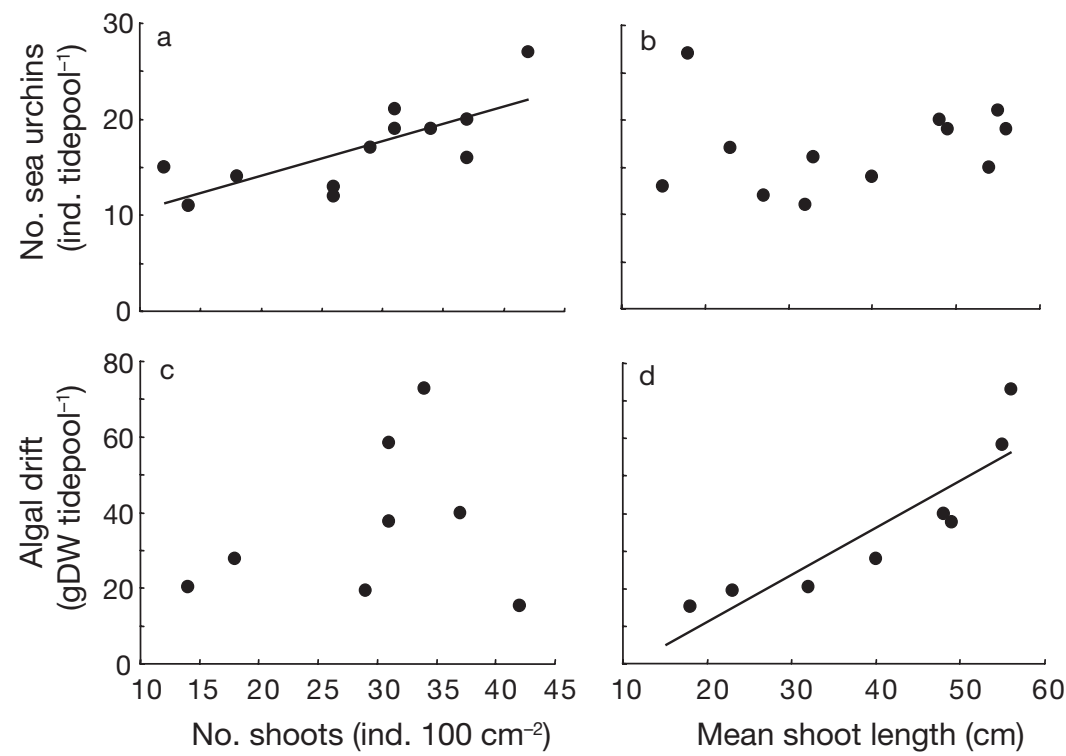

Fig. 1. Relationships between characteristics of surfgrass stands and allochthonous resource input. Total number of sea urchins entering each tide pool during the experiment with (a) shoot density $\left(y=0.362 x+6.840, R^{2}=0.569, p=0.005\right)$ and (b) mean shoot length $\left(\mathrm{R}^{2}=0.021, \mathrm{p}=0.656\right)$, and total amount of subtidal algal drift entering each tide pool during the short-term experiment with (c) shoot density $\left(R^{2}=0.5685, p=0.570\right)$ and $(d)$ mean shoot length $(y=1.255 x-$ 13.939, $\left.\mathrm{R}^{2}=0.795, \mathrm{p}=0.003\right)$

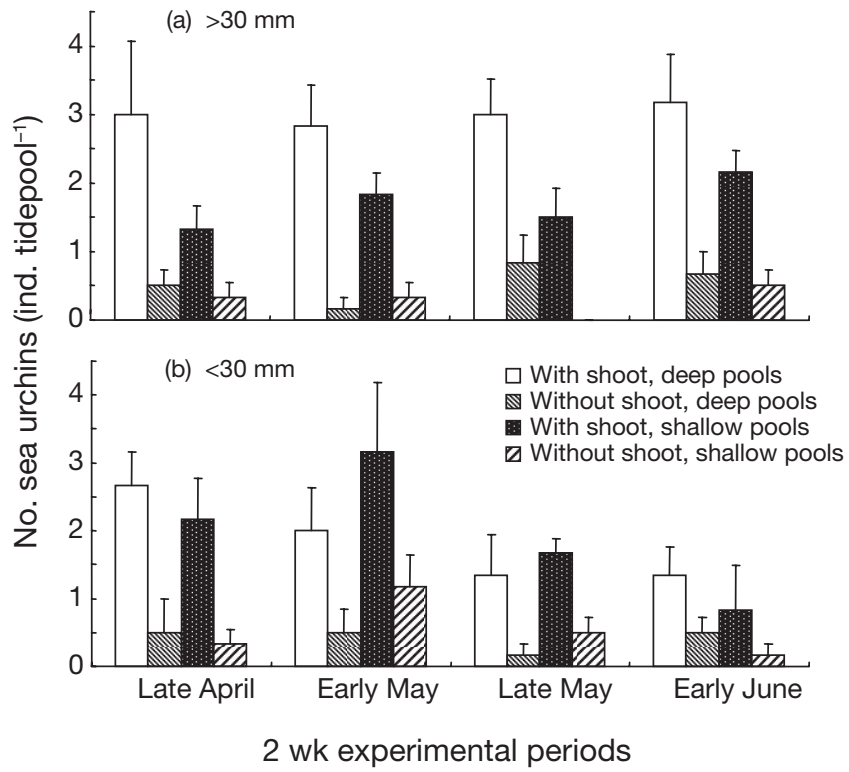

Fig. 2. Number of sea urchins in tide pools 2 wk after removal in repeated manipulations from April to June 2001 (mean $\pm 1 \mathrm{SE}, \mathrm{N}=6$ ). (a) individuals $>30 \mathrm{~mm}$ diameter, (b) individuals $<30 \mathrm{~mm}$ in diameter

but not to shoot density (Fig. 1c). The amounts of algal drift differed significantly between the surfgrass shoot manipulations and between tide pools with and without gastropods using a 3-way ANOVA (surfgrass shoot: $F=113.151, \mathrm{p}<0.0001$ : gastropod: $F=11.291, p=0.002$; Fig. 4 ). In both the treatments with and without algal drift, the number of gastropods was significantly higher in the tide pools with shoots than in those without (Fig. 5, Table 1), although the differences in the treatment without algal drift were smaller than in the treatment with algal drift (Fig. 5). This result suggests that shoot removal also has some effects on gastropods even when algal drift is absent.

In the long-term experiment, the shoot-cutting and algal-drift manipulations significantly decreased the number of gastropods (Fig. 6, Table 2). Univariate tests revealed that both the shoot-cutting manipulation and algal drift exclusion, decreased both the size (shoot cutting: $\mathrm{MS}=79.715, F=31.797$, $\mathrm{p}<0.001$; algal drift: $\mathrm{MS}=21.943, F=$ $8.753, \mathrm{p}=0.009$ ) and number (shoot cutting: $\mathrm{MS}=425.042, F=20.002$, $\mathrm{p}<0.001$; algal drift: $\mathrm{MS}=117.042$, $F=5.508, \mathrm{p}=0.032$ ) of gastropods. 
Table 1. The results of nested ANOVAs on the effect of surfgrass shoot (with vs. without shoot stand) and depth (deep vs. shallow) on the number of sea urchins entering tide pools, and ANOVAs on the effect of the surfgrass shoot and depth on the number of gastropods entering tide pools

\begin{tabular}{|c|c|c|c|c|c|c|c|}
\hline Source of variation & $\mathrm{df}$ & MS & $F$ & $\mathrm{p}$ & MS & $F$ & $\mathrm{p}$ \\
\hline \multicolumn{8}{|l|}{ Sea urchin input: } \\
\hline & & \multicolumn{3}{|c|}{$\geq 30 \mathrm{~mm}$ diameter } & \multicolumn{3}{|c|}{$<30 \mathrm{~mm}$ diameter } \\
\hline Depth & 1 & 1.538 & 13.605 & 0.0031 & 0.021 & 0.055 & 0.8178 \\
\hline Surfgrass shoot & 1 & 17.355 & 153.562 & $<0.0001$ & 9.263 & 23.948 & 0.0004 \\
\hline Depth $\times$ Surfgrass shoot & 1 & 0.322 & 2.847 & 0.1173 & 0.077 & 0.200 & 0.6629 \\
\hline Season $($ Depth $\times$ Shoot stand $)$ & 12 & 0.113 & 0.735 & 0.7135 & 0.387 & 1.630 & 0.0999 \\
\hline Residual & 80 & 0.154 & & & 0.237 & & \\
\hline \multicolumn{8}{|l|}{ Number of gastropods: } \\
\hline & & \multicolumn{3}{|c|}{ With algal drift } & $-\mathrm{r}$ & out alga & $\mathrm{ft} \longrightarrow$ \\
\hline Depth & 1 & 22.042 & 1.793 & 0.196 & 5.042 & 0.602 & 0.447 \\
\hline Surfgrass shoot & 1 & 672.042 & 54.675 & $<0.001$ & 45.375 & 5.418 & 0.031 \\
\hline Depth $\times$ Surfgrass shoot & 1 & 26.042 & 2.119 & 0.161 & 5.042 & 0.602 & 0.447 \\
\hline Residual & 20 & 12.292 & & & 8.375 & & \\
\hline
\end{tabular}

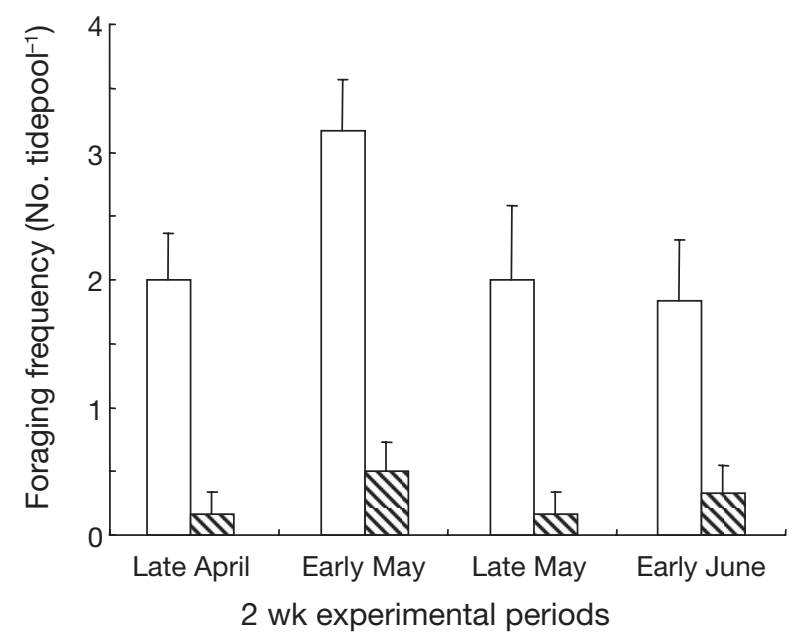

Fig. 3. Frequency of crows foraging on sea urchins (mean $\pm 1 \mathrm{SE}, \mathrm{N}=6$ ) in shallow tide pools from observations over repeated 2 wk periods (April to June 2001). Open bars show the foraging frequency in tide pools with surfgrass shoots; hatched bars show the foraging frequency in tide pools without shoots

Although the interactive effect between shoot cutting and algal drift was of little significance (Table 2), the shoot-cutting manipulation without algal drift likely affected the gastropods.

\section{DISCUSSION}

The shoot cutting manipulation significantly affected the amounts of both sea urchins and algal drift entering the intertidal tide pools (Fig. $2 \& 4$ ), although the characteristics of surfgrass that were positively related to algal drift differed from the characteristics related to sea urchin abundance (Fig. 1a,b).

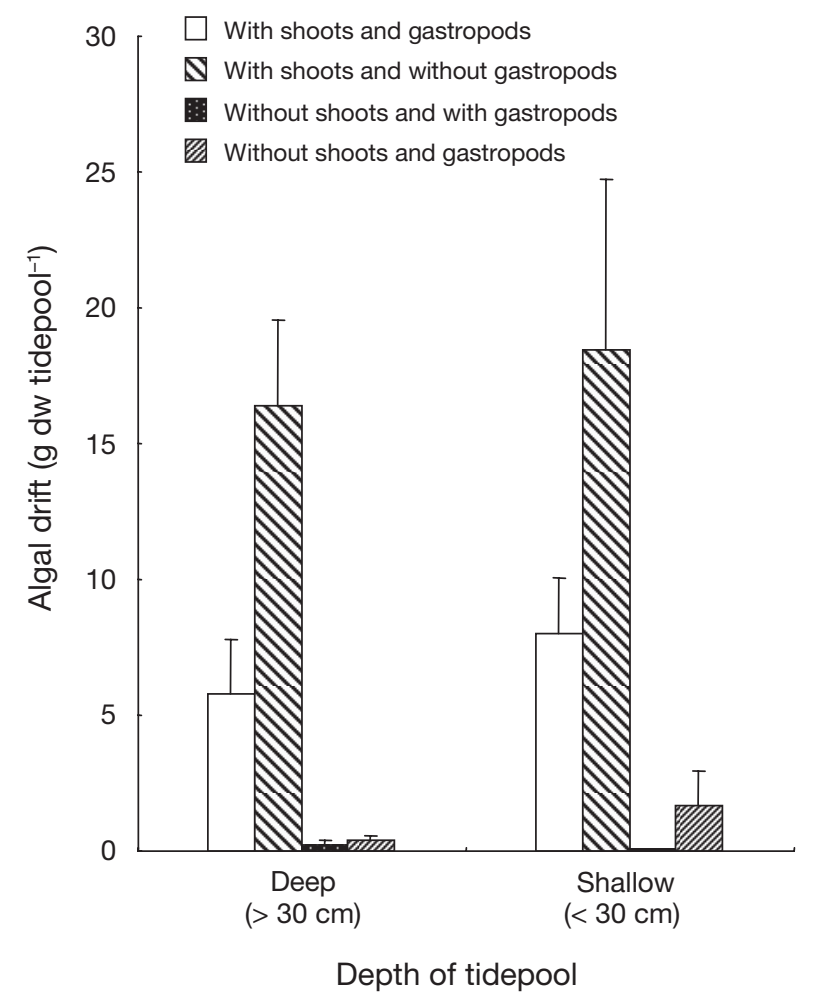

Fig. 4. Amount of subtidal algal drift (g dry weight [dw], mean $\pm 1 \mathrm{SE}$ ) entering deep and shallow tide pools manipulated over three 2 wk periods from June to August 2001. Each treatment therefore had 6 replicates

These differences may reflect variations in the inflow process and in the way that the surfgrass traps each allochthonous resource. For the spherical sea urchins, surfgrass shoots may function as a thick wall that stops and anchors them because sea urchins are likely to be transported by wave action during high tide, sinking and skimming over the bottom surface of the 


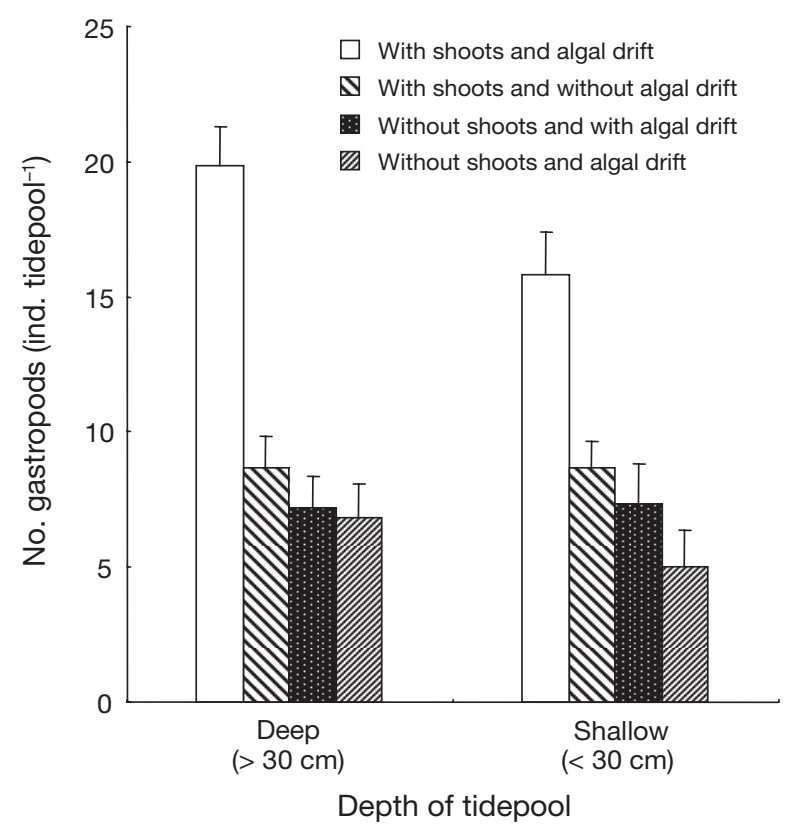

Fig. 5. Number of gastropods (mean $+1 \mathrm{SE}$ ) in tide pools manipulated during the short-term (2 wk) experiment replicated over three $2 \mathrm{wk}$ periods

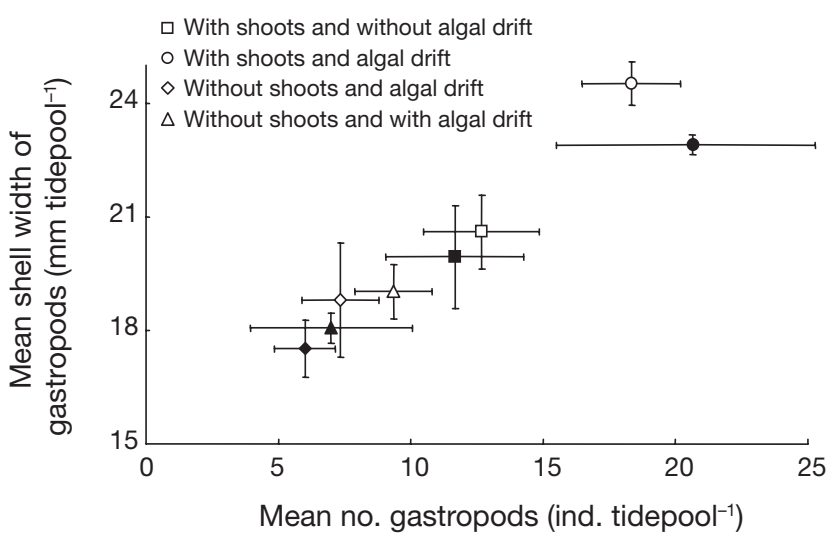

Fig. 6. Results of the shoot-cutting and algal-drift manipulations over the long term (1 yr). Each symbol shows the mean shell width and the mean number of gastropods in each tide pool treatment (mean $\pm 1 \mathrm{SE}$ ). Open and closed symbols indicate data of shallow and deep tide pools, respectively

Table 2. The result of MANOVA on the effect of depth (shallow vs. deep), surfgrass shoots (with vs. without) and algal drift (with vs. without) on the no. of gastropods in tide pools for the long-term experiment. $\mathrm{df}=2,15$

\begin{tabular}{|lrrr|}
\hline Source of variance & Wilks' $\lambda$ & \multicolumn{1}{c|}{$F$} & \multicolumn{1}{c|}{$\mathrm{p}$} \\
\hline Shoot stand & 0.284 & 18.889 & $<0.001$ \\
Algal drift & 0.591 & 5.200 & 0.019 \\
Depth & 0.836 & 1.468 & 0.262 \\
Shoot stand $\times$ Algal drift & 0.716 & 2.978 & 0.081 \\
Shoot stand $\times$ Depth & 0.970 & 0.232 & 0.796 \\
$\times$ Algal drift & 0.986 & 0.106 & 0.900 \\
Shoot stand $\times$ Algal drift $\times$ Depth & 0.951 & 0.389 & 0.684 \\
\hline
\end{tabular}

rocky platform rather than floating in the water (Hori 2003). In this case, shoot density is likely to be more important than shoot length in trapping the sea urchins. Algal drift is dominated by subtidal brown kelp with long and broad leaf morphology (Bustamante et al. 1995, Hori 2003), which is likely transported from subtidal habitats by floating with the wave action. In this case, long shoots that reach the surface of the water may be more effective in trapping and ensnaring algae, while shoot density is less important. At the study site, it was actually observed that algal drift was frequently entwined with the upper parts of surfgrass shoots (M. Hori pers. obs.).

Although the removal of surfgrass shoots lowered the amount of allochthonous resources trapped in the tide pools, it is not clear whether this was due to the effects of surfgrass trapping allochthonous matter. Regarding the relationships among surfgrass shoots, sea urchin abundance, and carrion crow foraging, another interpretation could also be considered. Crows or other predators foraging on the sea urchins trapped in shootless tide pools may have caused the observed differences in abundance of sea urchins in tide pools with and without shoots. However, the amount of sea urchins consumed by crows was significantly higher in tide pools with surfgrass shoots (Fig. 3), and the presence of surfgrass shoots significantly increased not only the amount of sea urchins $>30 \mathrm{~mm}$ but also those $<30 \mathrm{~mm}$ in diameter that were not consumed by crows (Fig. 3), suggesting that the number of sea urchins trapped in the tide pools was positively correlated with shoot density. Moreover, no other consumers were observed during any experimental period (M. Hori pers. obs.), although herring gulls Larus argentatus, slaty-backed gulls L. schistisagus, and Japanese jungle crows Corvus macrorhynchos also occasionally forage on sea urchins in the study area (Hori \& Noda 2001). These facts indicate that the presence of surfgrass shoots is likely to increase the consumption of sea urchins by crows by increasing sea urchin abundance, rather than by causing an obstruction that prevents the crows from foraging on sea urchins. The crows probably know where to catch sea urchins, even in tide pools where surfgrass shoots may cover the urchins during low tide (M. Hori pers. obs.).

In the experiment evaluating the short-term effects of surfgrass shoots on the number of gastropods and their aggregative response, shoot cutting caused the number of gastropods to decrease in tide pools with and without algal drift, although the difference in gastropod abundance between tide 
pools with and without shoots was higher in tide pools with algal drift (Fig. 4, Table 2). Two different hypotheses may explain why the number of gastropods decreased in tide pools without surfgrass shoots. One reason may be the decrease in algal drift, which is a food resource for gastropods, and the other may be the increase in environmental stress for gastropods as a result of the shoot-cutting manipulation. Tide pools with surfgrass usually contain few algae that can be consumed by gastropods, probably because surfgrass often covers and shades the surface of tide pools (BrinckmannVoss 1996), suggesting that there are few alternative food resource in these tide pools (M. Hori pers. obs.). In addition, subtidal algal drifts are normally superior food sources, relative to intertidal algae for intertidal herbivorous gastropods (Duggins \& Eckman 1997, Akahoshi 2001), and thus gastropods may show a preference for subtidal kelp drifts. These facts imply that gastropods should aggregate in tide pools with abundant algal drifts (Akahoshi 2001). Moreover, if shoot stands relieve environmental stresses such as heat or ultraviolet light, the number of gastropods should be significantly lower in shallow tide pools with reduced water volume. However, there was no significant difference in the number of gastropods in shallow and deep tide pools (Fig. 5, Table 1). Predation pressure on gastropods may also be considered an environmental stress, but no predators were present during the experimental period (Hori \& Noda 2001). Therefore, the first hypothesis is likely to be more plausible than the second one over the short term, although surfgrass shoots probably influence gastropods in ways other than simply through allochthonous resource provision, e.g. by mitigating environmental stresses.

In the long-term experiment evaluating the numerical response of gastropods to the presence/absence of surfgrass shoots and algal drift, both shoot cutting and exclusion of algal drift decreased the number and the mean size (and thus biomass) of gastropods. This implies that gastropods are responded, both functionally and numerically, to the amounts of algal drift associated with the shoot-cutting manipulations. The interaction between the shoot-cutting and the algal drift manipulation was not significant (Table 2), indicating that even without the algal drift, shoot cutting significantly affected the gastropods. Although there was no difference in gastropod density and size between deep and shallow pools (Table 2) as in the short-term experiment, some environmental factors caused by shoot cutting, other than the change in the amount of algal drift, may have negatively affected the gastropods. Consequently, the results of both the short- and long-term experiments suggest that surfgrass stands positively influence gastropods not only in their functional response, but also in their numeri- cal response, mainly by increasing the algal drift input and partly by relieving other environmental stresses.

In general, seagrasses have various ecological functions; in particular, trophic support is a major function that provides remarkably high rates of secondary productivity by increasing the in situ primary production (e.g. epiphytes on seagrass leaves) that is directly utilized by secondary consumers (Fredette et al. 1990, Heck et al. 1995). This study also revealed that surfgrass has architectural functions that can increase the abundance and biomass of secondary consumers, although this does not occur through the facilitation of in situ primary production but rather through the facilitation of allochthonous input from subtidal to intertidal habitats. Surfgrass will also affect the flux of various allochthonous resources. For example, the input and sedimentation of phytoplankton from pelagic systems and particulate organic matter (POM) derived from subtidal kelp, which are important allochthonous food resources for mussels and other suspension feeders (Duggins et al. 1989, Bustamante \& Branch 1996, Duggins \& Eckman 1997), are also likely to be increased by surfgrass. This is because friction with leaf shoots reduces the momentum of flowing water so that the mean water flow speed decreases and sedimentation of small particles increases (Burrell \& Schubel 1977, Fonseca et al. 1982, Ackerman \& Okubo 1993). Therefore, surfgrass may affect the community structure and dynamics of rocky intertidal habitats by regulating most allochthonous subsidies.

In conclusion, these architectural effects of surfgrass are not functions that are distinctive to surfgrass in the rocky intertidal habitat; other plants with large 3D structures in other habitats should also possess these functions. For example, trees in riparian forests may trap allochthonous resources such as salmon carcasses from rivers (Ben-David et al. 1998), and intertidal mangroves can trap allochthonous resources from terrestrial and/or subtidal habitats (Brinkman et al. 2005). Other seagrass species may trap allochthonous resources from terrestrial habitats through river inputs because seagrass meadows are often established in estuaries near the river mouth (Hemminga \& Duarte 2000, Short et al. 2001). Therefore, in habitats with organisms that can establish sizeable structures, further attention to architectural traps of allochthonous resources may be needed to clarify the effects and processes governing allochthonous subsidies.

Acknowledgements. I thank T. Noda for his support and valuable comments on this research. I am also grateful to N. Iino and Y. Miyamoto for logistical support and M. Takada for comments on the manuscript. N. Kato encouraged me to write the manuscript. This study was supported by a JSPS research fellowship for young scientists. 


\section{LITERATURE CITED}

Ackerman JD, Okubo A (1993) Reduced mixing in a marine macrophyte canopy. Funct Ecol 7:305-309

Akahoshi S (2001) The effect of subtidal kelp subsidization on a herbivorous gastropod and intertidal algal community. MS thesis, Hokkaido University, Japan

Ben-David M, Hanley TA, Schell DM (1998) Fertilization of terrestrial vegetation by spawning pacific salmon: the role of flooding and predator activity. Oikos 83:47-55

Brinckmann-Voss A (1996) Seasonality of hydroids (Hydrozoa, Cnidaria) from an intertidal pool and adjacent subtidal habitats at Race Rocks, off Vancouver Island, Canada. Sci Mar 60:89-97

Brinkman R, Wattayakorn G, Wolanski E, Spaqnol S, Marshall K (2005) Storm-deriven erosion of fine sediment and its subsequent transport and trapping in fringing mangroves, Sawi Bay, Thailand. J Coast Res Spec Issue 42: 211-220

Burrell DC, Schubel JR (1977) Seagrass ecosystem oceanography. In: McRoy CP, Helfferich C (eds) Seagrass ecosystems: a scientific perspective. Dekker, New York, USA, p 195-232

Bustamante RH, Branch GM (1996) The dependence of intertidal consumers on kelp-derived organic matter on the west coast of South Africa. J. Exp Mar Biol Ecol 196:1-28

Bustamante RH, Branch GM, Eekhout S (1995) Maintenance of an exceptional intertidal grazer biomass in South Africa: subsidy by subtidal kelp. Ecology 76:2314-2329

Duggins DO, Eckman JE (1997) Is kelp detritus a good food for suspension feeders? Effects of kelp species, age and secondary metabolite. Mar Biol 128:489-495

Duggins DO, Simenstadand CA, Estes JA (1989) Magnification of secondary production by kelp detritus in coastal marine ecosytems. Science 245:170-173

Fonseca MS, Fisher JS, Zieman JC, Thayer GW (1982) Influence of the seagrass, Zostera marina L., on current flow. Estuar Coast Mar Sci 15:351-364

Fredette TJ, Diaz RJ, van Montfrans J, Orth RJ (1990) Secondary production within a seagrass bed (Zostera marina and Ruppia maritima) in lower Chesapeake Bay. Estuaries 13:431-440

Hasegawa N, Iizumi H, Mukai H (2005) Nitrogen dynamics of the surfgrass Phyllospadix iwatensis. Mar Ecol Prog Ser 293:59-68

Heck KLJ, Able KW, Roman CT, Fahay MP (1995) Composition, abundance, biomass and production of macrofauna in a New England estuary: comparison among eelgrass meadows and other nursery habitats. Estuaries 18:379-389

Hemminga MA, Duarte CM (2000) Seagrass ecology, 1st edn. Cambridge University Press, Cambridge

Editorial responsibility: Howard I. Browman (Associate Editor-in-Chief), Storebø, Norway
Hori M (2003) Food web structure and dynamics attributed to avian foraging and allochthonous input in the rocky intertidal habitat. $\mathrm{PhD}$ thesis, Hokkaido University

Hori M, Noda T (2001) An unpredictable indirect effect of algal consumption by gulls on crows. Ecology 82: $3251-3256$

Menge BA, Branch GM (2001) Rocky intertidal communities. In: Bertness MD, Gaines SD, Hay ME (eds) Marine community ecology. Sinauer Associates, Sunderland, MA, p 221-252

Menge BA, Daley BA, Wheeler PA, Dahlhoff E, Sanford E, Strub PT (1997a) Benthic-pelagic links and rocky intertidal communities: bottom-up effects or top-down control? Proc Natl Acad Sci USA 94:14530-14535

Menge BA, Daley BA, Wheeler PA, Strub PT (1997b) Rocky intertidal oceanography: an association between community structure and nearshore phytoplankton concentration. Limnol Oceanogr 42:57-66

Polis GA, Hurd SD (1995) Extraordinarily high spider densities on islands: flow of energy from the marine to terrestrial food webs and the absence of predation. Proc Natl Acad Sci USA 92:4382-4386

Polis GA, Hurd SD (1996) Linking marine and terrestrial food webs: allochthonous input from the ocean supports high secondary productivity on small islands and coastal land communities. Am Nat 147:396-423

Polis GA, Strong DR (1996) Food web complexity and community dynamics. Am Nat 147:813-846

Polis GA, Anderson WB, Holt RD (1997) Towards an integration of landscape and food web ecology: the dynamics of spatially subsidized food webs. Annu Rev Ecol Syst 28: 289-316

Sabo JL, Power ME (2002a) River-watershed exchange: effects of riverine subsidies on riparian lizards and their terrestrial prey. Ecology 83:1860-1869

Sabo JL, Power ME (2002b) Numerical response of lizards to aquatic insects and short-term consequences for terrestrial prey. Ecology 83:3023-3036

Short FT, Coles RG, Pergent-Martini C (2001) Global seagrass distribution. In: Short FT, Coles RG (eds) Global seagrass research methods. Elsevier Science, Amsterdam

Turner T (1985) Stability of rocky intertidal surfgrass bedspersistence, preemption, and recovery. Ecology 66:83-92

Williams SL, Heck KLJ (2001) Seagrass community ecology. In: Bertness MD, Gaines SD, Hay ME (eds) Marine community ecology. Sinauer Associates, Sunderland, MA, p 317-339

Yabe T, Ikushima I, Tsuchiya T (1995) Production and population ecology of Phyllospadix iwatensis Makino 1. Leaf growth and biomass in an intertidal zone. Ecol Res 10: 291-299

Submitted: October 5, 2005; Accepted: December 15, 2005 Proofs received from author(s): April 5, 2006 